\title{
Isolation, structure characteristics and antioxidant activity of two water-soluble polysaccharides from Lenzites betulina
}

Lei Guo ${ }^{1,2}$, Hongwei Dai ${ }^{2}$, Jiayu Ma' ${ }^{1}$ Junmin Wang ${ }^{1}$, Yan Hua ${ }^{* *}$ and Lingyun Zhou ${ }^{3 *}$

\begin{abstract}
Background: Fungal polysaccharides belong to a very important class of biological macromolecules in nature, and have complex monosaccharide composition and structure. These studies on structure and biological activity of fungal polysaccharides have become one of the research hotspots of scholars at home and abroad.

Results: This study was performed in order to understand the structural characteristics and antioxidant activity of polysaccharides from Lenzites betulina (LBPs). The LBPs were deproteinized using sevag method, and further purified by DEAE cellulose-52 column and Sephadex G-100 column chromatographies, then the two refined polysaccharides were obtained and named LBPs-5 and LBPs-6. Fourier transform infrared spectrometry (FT-IR) showed that LBPs-5 and LBPs- 6 are typical $\beta$-pyranose with characteristic peaks of polysaccharides. The molecular weight of the two watersoluble polysaccharides were estimated to be $3.235 \times 10^{3} \mathrm{Da}$ and $6.196 \times 10^{3} \mathrm{Da}$ by HPGPC, respectively. HPLC with PMP derivatization analysis indicated that the monosaccharide compositions of LBPs- 5 were mannose, glucuronic acid, glucose, and galactose in a molar ratio of $0.05: 0.15: 0.76: 0.04$. The monosaccharide compositions of LBPs- 6 were mannose, glucuronic acid, and glucose, in a molar ratio of 0.04:0.17:0.79. Furthermore, the two water-soluble polysaccharides demonstrated strong scavenging effects on DPPH $\cdot$, ABTS. ${ }^{+}, \cdot \mathrm{OH}$ and weak total reducing power, especially LBPs-6 was significantly stronger in scavenging rate than that of LBPs-5.
\end{abstract}

Conclusions: The outcome of the study indicated that LBPs had good potential as medicine and food.

Keywords: Lenzites betulina, Polysaccharides, Deproteinization, Purification, Structure characteristics, Antioxidant activity

\section{Introduction}

Natural plant polysaccharides are a very important class of biological macromolecules in plants, which are composed of aldoses and ketoses through glycosidic bond, and are the basic substances that effectively maintain and ensure the normal operation of biological life activities $[1$,

\footnotetext{
*Correspondence: huayan1216@163.com; 737841486@qq.com

1 Key Laboratory for Forest Resources Conservation and Utilization

in the Southwest Mountains of China, Ministry of Education, Southwest

Forestry University, Kunming, People's Republic of China

${ }^{3}$ School of Pharmacy, Wannan Medical College, Wuhu, People's Republic

of China

Full list of author information is available at the end of the article
}

2]. Fungal polysaccharides have a variety of physiological activities and are widely used in medicine, agriculture, food and other industries [3-5]. They have various physiological functions such as immune regulation, antitumor, antiviral and antioxidant [6-9]. They can be used as natural immunomodulator. These studies have become one of the research hotspots of scholars at home and abroad. The chemical structure of fungal polysaccharides plays an important role in their biological activities, including their molecular configuration, molecular weight, branched chains, branched groups and main chains [10].

Lenzites betulina (L.) Fr. is a medicinal mushroom and widely distributed in China, which is a Lenzites fungus 
belonging to the Polyporacea [11, 12]. Because of containing some physiologically active substances, such as polysaccharides, pyranone, sterol et al. Lenzites betulina has been used to treat haunch and femora pain, acropathy, apoplexy and cold [13-16]. However, little is known about the molecular structure and physiological function of polysaccharides from Lenzites betulina. Therefore, in this study, the crude polysaccharides from Lenzites betulina (LBPs) was deproteinized using sevag method, and purified sequentially by DEAE cellulose- 52 column and Sephadex G-100 column chromatographies, then two refined polysaccharides were obtained. Moreover, their structure characteristics, relative molecular weights $(\mathrm{Mw})$ and monosaccharide composition were determined. To the best of our knowledge, this is the first study to investigate the structural characteristics of polysaccharides from Lenzites betulina. It will lay a foundation for further understanding the biological activity mechanism of LBPs.

\section{Results and discussion Deproteinization of LBPs}

The protein removal rate and polysaccharide loss rate could be seen in Fig. 1. When the protein was removed, polysaccharides were partially removed at the same time. It was obvious that both protein and polysaccharides removal rate increased with increasing experiment times. The protein removal rate reached the maximum of $76.04 \%$ when the experimental was repeated 6 times, and the polysaccharides loss rate reached $45.58 \%$. After 6 times, the two indexes reached to a dynamic equilibrium with the experimental times increasing. Therefore, an experimental time of 6 was chosen for the further experiments.

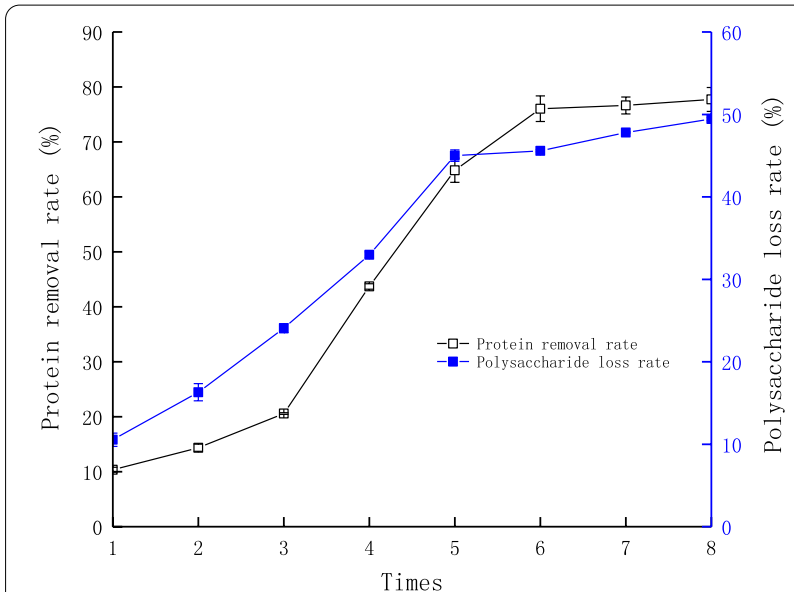

Fig. 1 Effects of experiments times on protein removal rate and polysaccharide loss rate
After deproteinization, the crude LBPs were concentrated and freeze-dried, and then the LBPs sample was obtained for further structure identification. The sample were resolved in distilled water and then scanned in the range of $200-400 \mathrm{~nm}$ by an ultraviolet spectrophotometer. The results of UV analysis showed that there was not absorption peak at $260 \mathrm{~nm}$ and $280 \mathrm{~nm}$, and it could proved that no protein or nucleic acid in the sample.

\section{Purification by DEAE cellulose- 52 column}

Purification of LBPs was performed by DEAE cellulose-52 column, and they were eluted with gradients of $0,0.1,0.2$ and $0.5 \mathrm{~mol} / \mathrm{L} \mathrm{NaCl}$ solutions. The fractions of the isolated LBPs were mainly concentrated in the elution solution. As shown in Fig. 2, four polysaccharides components were separated and obtained from LBPs. Among these, the content of LBPs- 1 and LBPs- 2 were higher than the other, so the two polysaccharides components were selected and further purified by the Sephadex G-100 column.

\section{Further purification by Sephadex G-100 column}

The two water-soluble polysaccharides of LBPs-1 and LBPs-2 were further purified using a Sephadex G-100 column, and the elution curve of them were shown in Fig. 3. After purification by G-100, two single eluting symmetrical peaks were obtained. The results indicated that the obtained polysaccharide of LBPs- 5 and LBPs- 6 were a relatively homogeneous polysaccharide.

\section{Fourier transform infrared (FT-IR) analysis}

Figure 4 showed the Fourier transform infrared (FTIR) spectra of dialyzed LBPs-3 and LBPs-4, which had

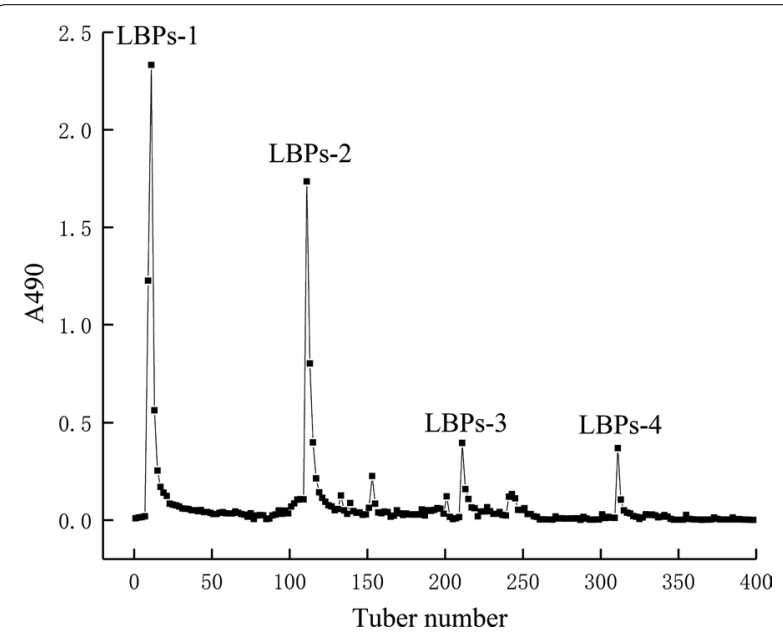

Fig. 2 Gradient elution profile of polysaccharides extracted from Lenzites betulina by DEAE cellulose- 52 chromatography 

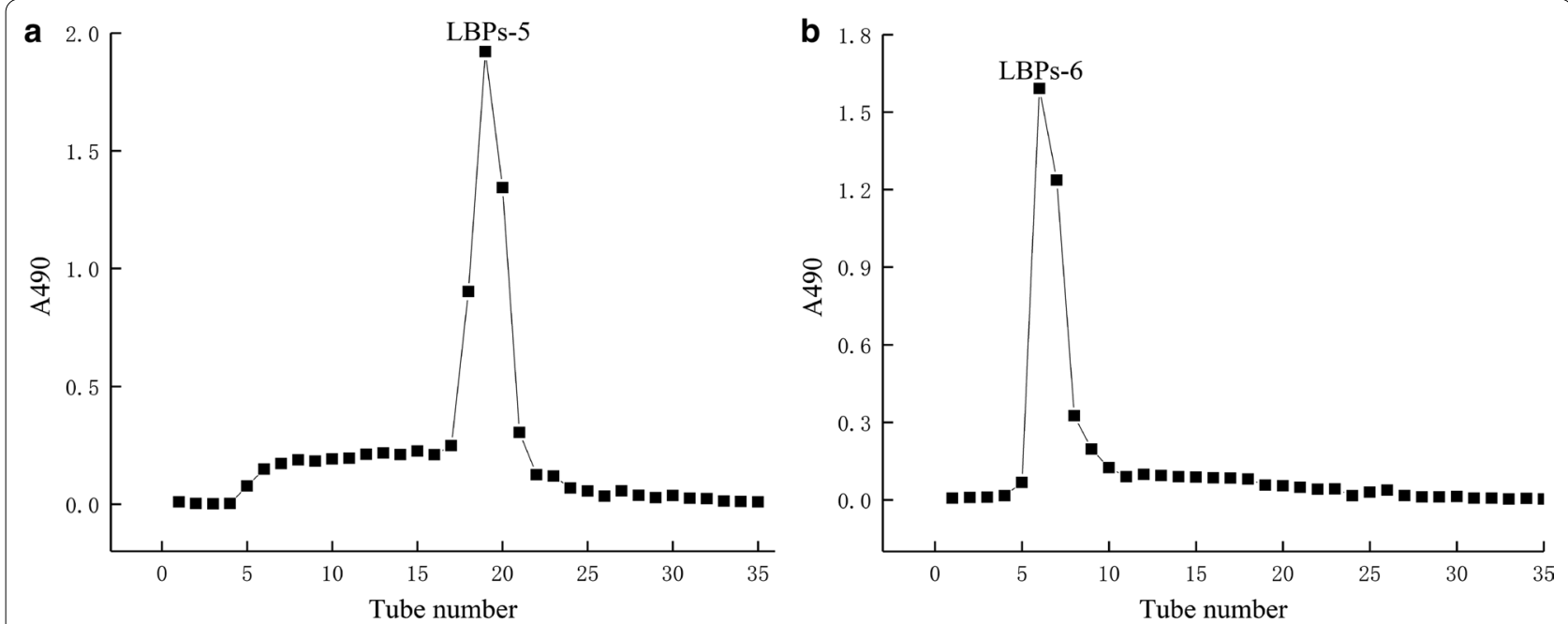

Fig. 3 Elution profile of polysaccharides LBPs-5 and LBPs-6 by G-100 column chromatography

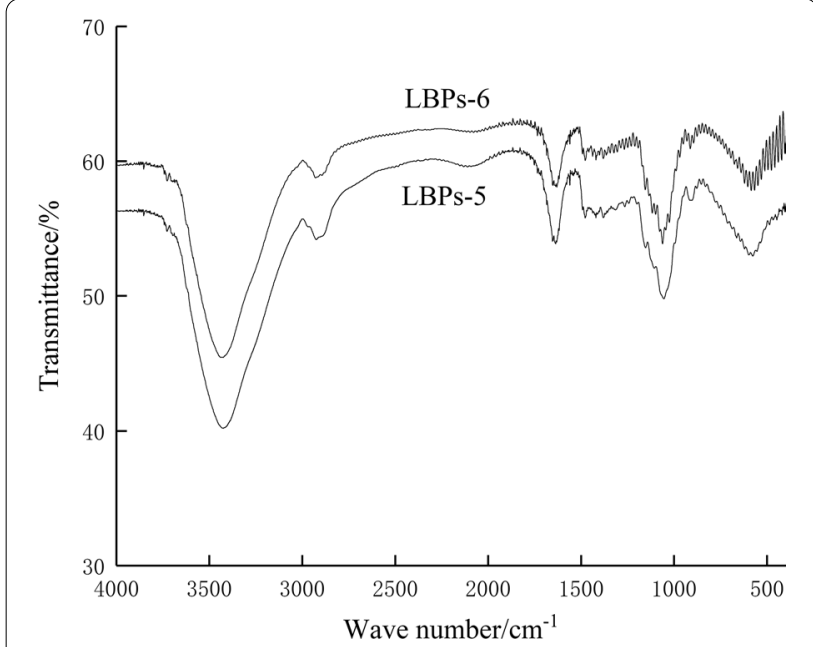

Fig. 4 The FT-IR spectrums of LBPs-5 and LBPs- 6

virtually identical characteristic absorption peaks. The strong and broad peak at around $3424 \mathrm{~cm}^{-1}$ was assigned to $(\mathrm{OH}-)$ stretching of polysaccharide residues and residual water (OH-). The signal at $2925 \mathrm{~cm}^{-1}$ was attributed to the asymmetric stretching vibrations of $(\mathrm{C}-\mathrm{H})$ groups of polysaccharides [17]. The bands at $\sim 1637 \mathrm{~cm}^{-1}$ (LBPs5), $1752 \mathrm{~cm}^{-1}$ (LBPs-6), $1546 \mathrm{~cm}^{-1}$ (LBPs-5), $1652 \mathrm{~cm}^{-1}$ (LBPs-6) were attributed to stretching vibration of $\mathrm{C}=\mathrm{O}$ $[18,19]$. The weak peaks observed at $1420 \mathrm{~cm}^{-1}$ (LBPs5), $1478 \mathrm{~cm}^{-1}$ (LBPs-6) indicated the stretching vibration of $\mathrm{C}-\mathrm{H}$ [20]. Peaks observed at $1054 \mathrm{~cm}^{-1}$ (LBPs-5) and $1078 \mathrm{~cm}^{-1}$ (LBPs-6) could be assigned to the contribution of $\mathrm{C}-\mathrm{O}-\mathrm{C}$ symmetric stretching vibration [21]. Sharp absorption peaks at $915 \mathrm{~cm}^{-1}$ and $912 \mathrm{~cm}^{-1}$ suggested the presence of $\beta$-glucosidic bond in the molecular structure of LBPs- 5 and LBPs-6 $[22,23]$. Weak absorption peaks at $554 \mathrm{~cm}^{-1}$ and $585 \mathrm{~cm}^{-1}$ suggested the characteristics of pyranoid ring in the molecular structure of LBPs-5 and LBPs-6 [21]. Overall, the outcomes of FT-IR spectra showed all typical absorption peaks associated with polysaccharides which confirmed the identity of LBPs-5 and LBPs- 6 as polysaccharides.

\section{Molecular weight determination}

The molecular weight of LBPs- 5 and LBPs- 6 were determined using high performance gel permeation chromatography (HPGPC). According to the regression equation $\left(\log \mathrm{Mw}=-1.7568 \mathrm{X}+2.334, \mathrm{R}^{2}=0.9976\right)$, the retention time of the LBPs-5 component was $22.922 \mathrm{~min}$. the Mw of LBPs-5 was approximately calculated as $3.235 \times 10^{3} \mathrm{Da}$. The retention time of LBPs- 6 component was $22.108 \mathrm{~min}$, and the $\mathrm{Mw}$ calculated on the basis of the regression equation was $6.196 \times 10^{3} \mathrm{Da}$.

\section{Monosaccharide composition}

The HPLC chromatograms of the PMP-derivatized component monosaccharides released from the polysaccharides fractions are shown in Fig. 5. The monosaccharide compositions of LBPs-5 were consisted of mannose, glucuronic acid, glucose, and galactose in a molar ratio of 0.05:0.15:0.76:0.04 (Fig. 5a). LBPs-6 was mainly composed of mannose, glucuronic acid, and glucose in a molar ratio of 0.04:0.17:0.79 (Fig. 5b). According to the results of the monosaccharide composition the two polysaccharides are heteroglucans. 


\section{a}

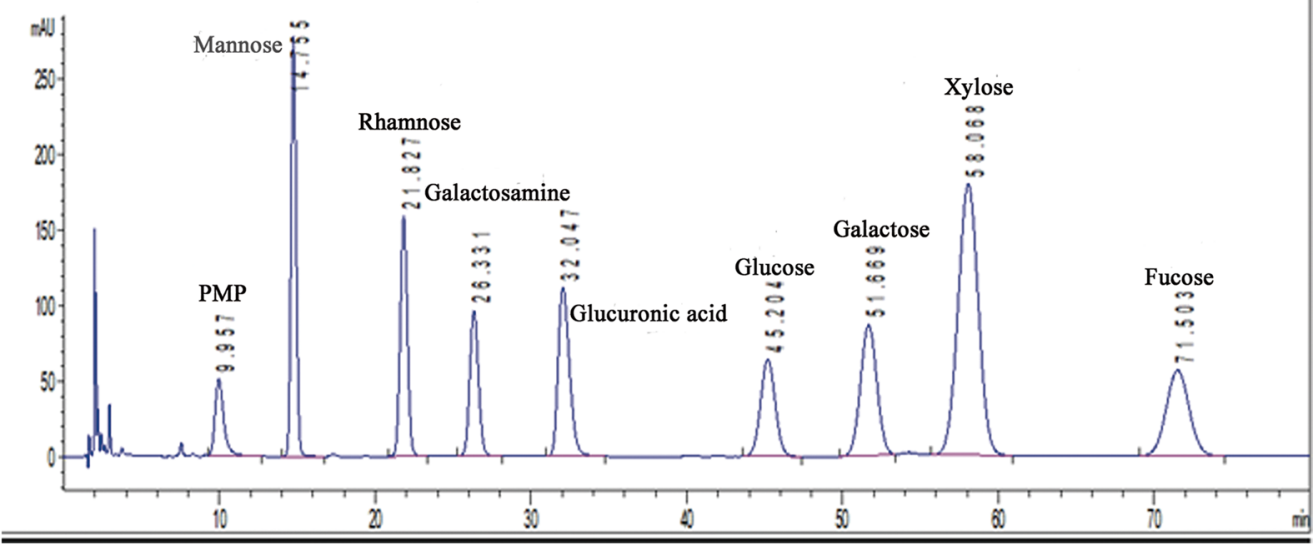

b

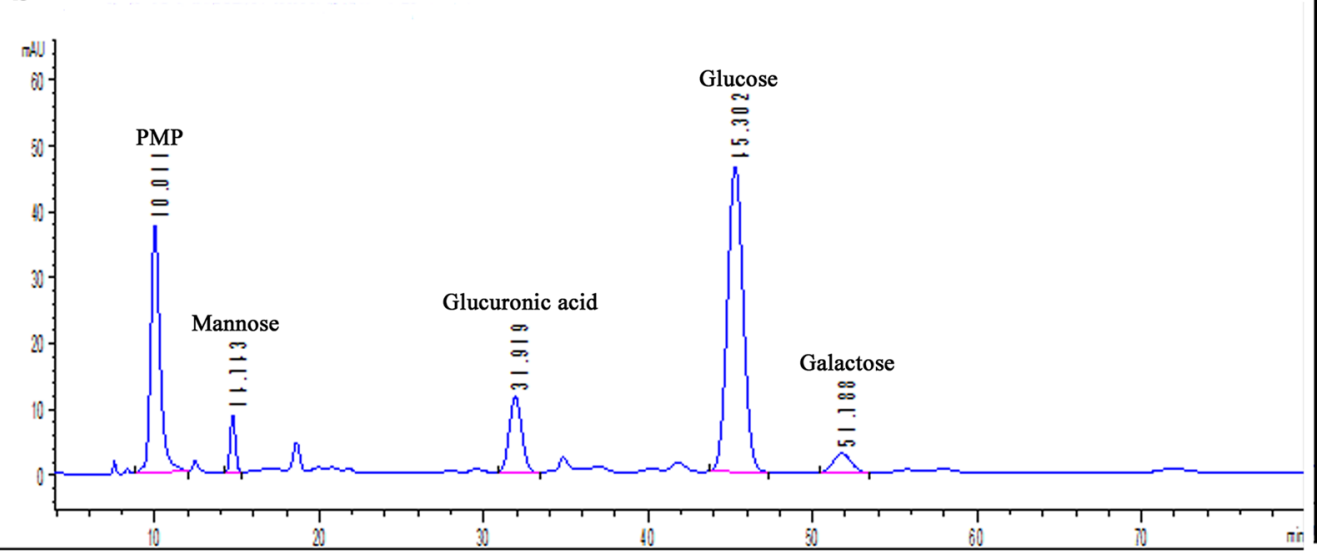

C

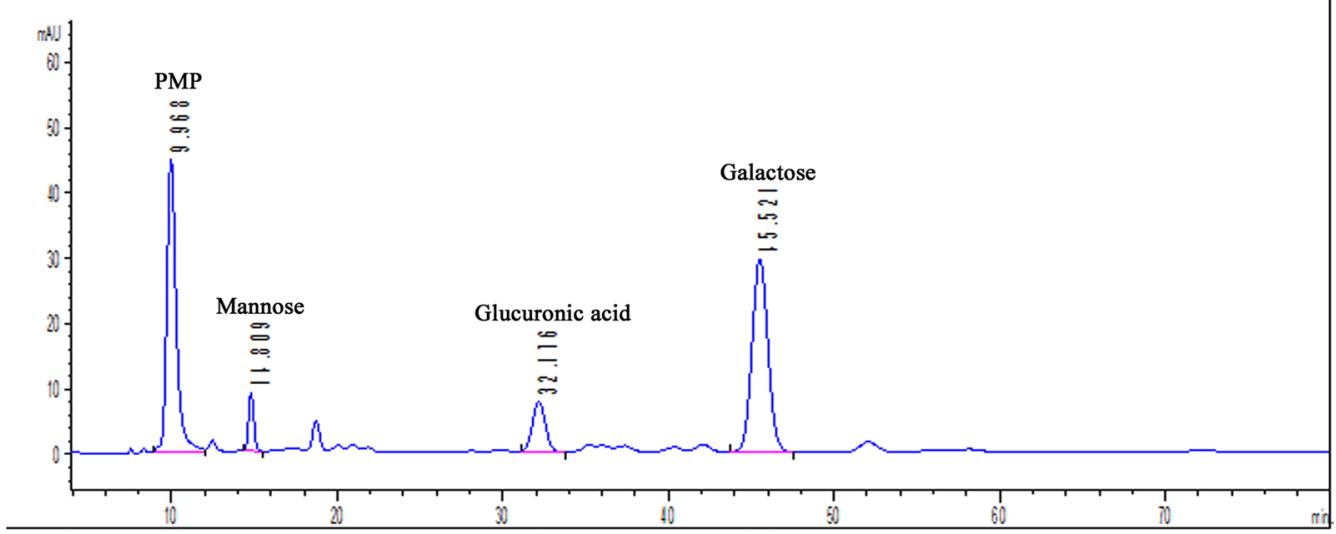

Fig. 5 HPLC spectra of monosaccharide compositions of Standard sample (a), LBPs-5 (b) and LBPs-6 (c)

\section{Antioxidant activities of the two water-soluble} polysaccharides

The assay of the scavenging of DPPH radical (DPPH.) is a widely applied method to evaluate the antioxidant activity of natural active ingredients from different plant origin [24]. Polysaccharides have many hydroxyl groups and most of them can donate hydrogen to reduce the DPPH. [25]. The DPPH. scavenging activity 
of the two water-soluble polysaccharides and Vc were shown in Fig. 6a. The results showed that LBPs-5 and LBPs-6 exhibited an inhibitory activity against DPPH. in a dose-dependent manner. The DPPH. scavenging activity of LBPs-5 and LBPs- 6 increased steadily at the concentration rang of $0.01-1.5 \mathrm{mg} / \mathrm{mL}$, while Vc displayed a maximum plateau from 0.01 to $0.1 \mathrm{mg} /$ $\mathrm{mL}$, indicating that the scavenging activity of the two water-soluble polysaccharides against $\mathrm{DPPH}$. were less than that of $\mathrm{Vc}$ at the same concentrations. The DPPH. scavenging activity of LBPs- 5 and LBPs- 6 were $46.31 \pm 0.71 \%$ and $87.96 \pm 0.97 \%$ at the concentration of $1.5 \mathrm{mg} / \mathrm{mL}(\mathrm{p}<0.05)$. As shown in Table 1 , the $\mathrm{EC}_{50}$ value of LBPs-5 and LBPs-6 were $1.66 \mathrm{mg} / \mathrm{mL}$ and $0.095 \mathrm{mg} / \mathrm{mL}$, while those of $\mathrm{Vc}_{\mathrm{c}}$ was $0.009 \mathrm{mg} / \mathrm{mL}$.

ABTS can generate turquoise and water soluble ABTS free radicals $\left(\mathrm{ABTS}^{+}\right)$after oxidized by potassium
Table $1 \mathrm{EC}_{50}$ values of various sample from Boletus edulis in antioxidant properties

\begin{tabular}{|c|c|c|c|}
\hline \multirow[t]{2}{*}{ Sample } & \multicolumn{3}{|l|}{$\mathrm{EC}_{50}$ value $(\mathrm{mg} / \mathrm{mL})$} \\
\hline & $\begin{array}{l}\text { DPPH. scavenging } \\
\text { activity }\end{array}$ & $\begin{array}{l}\text { ABTS }{ }^{+} \text {scavenging } \\
\text { activity }\end{array}$ & $\begin{array}{l}. \mathrm{OH} \\
\text { scavenging } \\
\text { activity }\end{array}$ \\
\hline LBPs-5 & $1.66^{c}$ & $1.369^{c}$ & $0.006^{a}$ \\
\hline LBPs-6 & $0.095^{b}$ & $0.031^{b}$ & $0.006^{\mathrm{a}}$ \\
\hline Ve & $0.009^{a}$ & $0.004^{a}$ & $0.010^{b}$ \\
\hline
\end{tabular}

$\mathrm{EC}_{50}$ value is half maximal inhibitory concentration. Data were presented as the mean value $(n=3)$. The superscript letters $a, b$, and $c$ indicate a significant difference at the 0.05 significance level

sulfate, and the characteristic absorption peak of which can be detected at $734 \mathrm{~nm}$. Fungal polysaccharides can scavenge $\mathrm{ABTS}^{+}$and further makes the turquoise
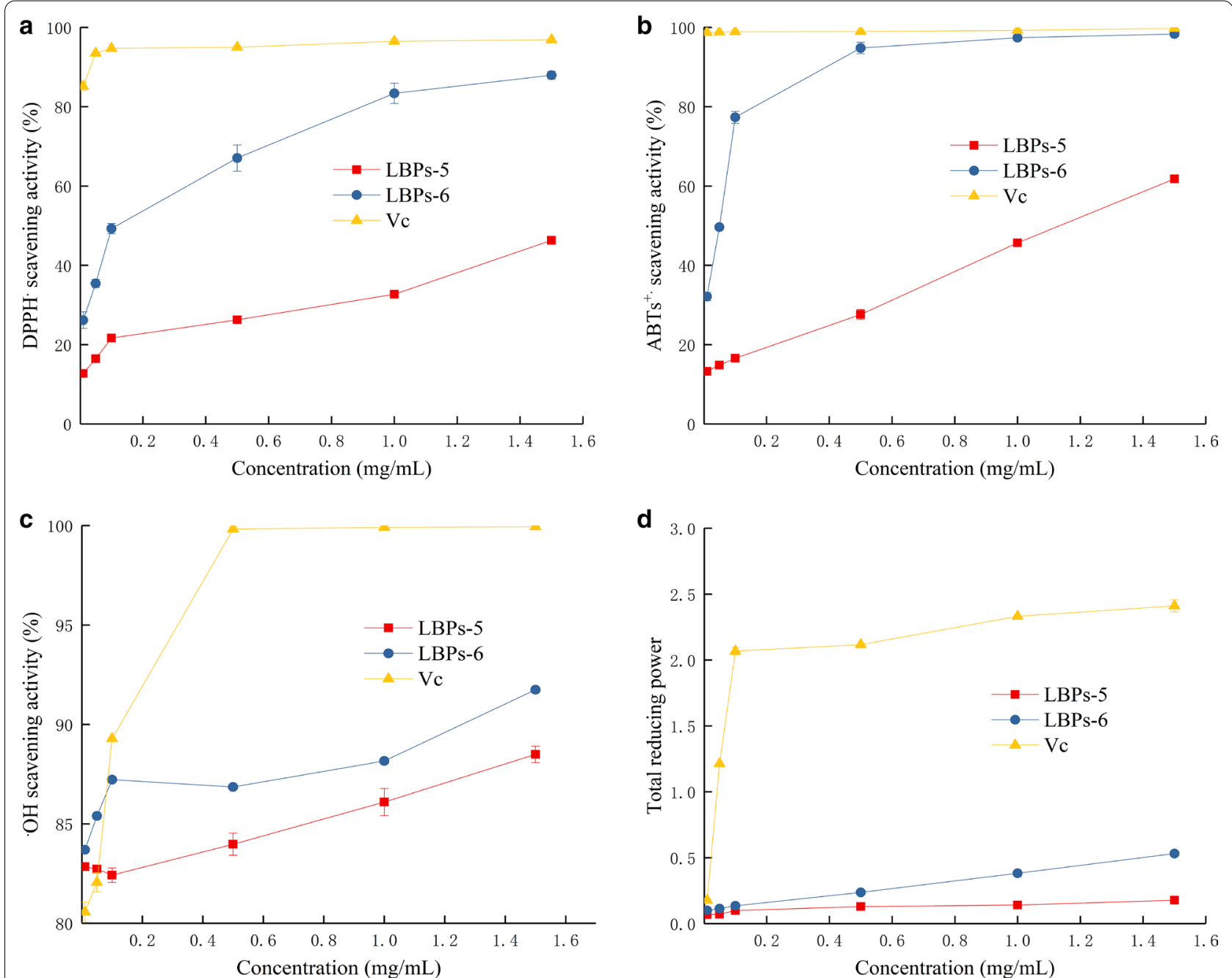

Fig. 6 Scavenging activities on DPPH. (a), ABTS ${ }^{+}(\mathbf{b}), \cdot \mathrm{OH}(\mathbf{c})$, and total reducing power (d) assay for LBPs-5, LBPs-6 and Vc at different concentrations 
solution fading, and the $\mathrm{ABTS}^{+}{ }^{+}$scavenging activity could be measured according to the fading degree [26]. Figure $6 \mathrm{~b}$ demonstrated the $\mathrm{ABTS}^{+}{ }^{+}$scavenging activity of the two water soluble polysaccharides and Vc. These findings indicated that LBPs- 5 exhibited higher ABTS ${ }^{+}$ scavenging activity than LBPs- 6 at all tested concentrations. The scavenging effects of three samples on the ABTS $^{+}$followed the order: Vc $>$LBPs- $6>$ LBPs- 5 and were $99.75 \pm 0.25 \%, 98.32 \pm 0.38 \%$, and $61.80 \pm 0.38 \%$ at the concentration of $1.5 \mathrm{mg} / \mathrm{mL}(\mathrm{p}<0.05)$, respectively. As shown in Table 1, the $\mathrm{EC}_{50}$ values corresponding to the $\mathrm{ABTS}^{+}$scavenging activity were found to be $1.369 \mathrm{mg} / \mathrm{mL}, 0.031 \mathrm{mg} / \mathrm{mL}$, and $0.004 \mathrm{mg} / \mathrm{mL}$ for the original LBPs-5, LBPs-6, and Vc, respectively.

Hydroxyl radicals $(\cdot \mathrm{OH})$ could be byproducts of immune action, which are highly reactive and can damage various macromolecules, such as carbohydrates, lipids and amino acids and are very harmful to human health [27]. The production of $\cdot \mathrm{OH}$ is dependent on the content of $\mathrm{Fe}^{2+}$ and $\mathrm{H}_{2} \mathrm{O}_{2}$ according to the Fenton reaction [28]. The scavenging effects of LBPs-6 and LBPs-5 on $\cdot \mathrm{OH}$ were shown in Fig. 6c. LBPs-5 and LBPs-6 demonstrated stronger $\cdot \mathrm{OH}$ scavenging activities than $\mathrm{Vc}$ at concentrations from 0.01 to $0.05 \mathrm{mg} / \mathrm{mL}(\mathrm{p}<0.05)$. At a concentration of $0.01 \mathrm{mg} /$ $\mathrm{mL}$, the $\cdot \mathrm{OH}$ scavenging activity increased in the order of Vc $<$ LBPs- $5<$ LBPs- 6 and were $80.57 \pm 0.50 \%$, $82.85 \pm 0.05 \%$, and $83.70 \pm 0.09 \%$, respectively. Table 1 demonstrated the $\mathrm{EC}_{50}$ values of scavenging $\cdot \mathrm{OH}$ of various samples, and the findings indicated that LBPs-5 and LBPs- 6 were observed to posses highly $\cdot \mathrm{OH}$ scavenging potential than that of Vc.

The total reducing power is generally associated with the presence of reductones, which could donate a hydrogen atom and exert antioxidant action by breaking the free radical chain [29]. The total reducing power of an active compound could serve as a important indicator of its potential antioxidant activity. The total reducing power of all three samples were measured at $700 \mathrm{~nm}$ and shown in Fig. 6d. The total reducing power of LBPs-6 and LBPs-5 increased with increasing concentrations. The total reducing power increased from 0.1 to 0.53 when the concentration of LBPs- 6 changed from $0.01 \mathrm{mg} / \mathrm{mL}$ to $1.5 \mathrm{mg} / \mathrm{mL}$. In addition, the total reducing power of LBPs-5 was lower than that of LBPs- 6 at the same concentration, it reached 0.177 at a concentration of $1.5 \mathrm{mg} /$ $\mathrm{mL}$.

The antioxidant tests indicated that both of LBPs- 5 and LBPs-6 have demonstrated the good scavenging activities on the three radicals (DPPH., $\mathrm{ABTS}^{+}{ }^{+}$, and $\cdot \mathrm{OH}$ ) and the total reducing power, especially LBPs-6 was slightly stronger in antioxidant activity than that of LBPs-5. In general, the antioxidant activities of polysaccharides are highly associated with the glucuronic acid content. Wu et al. [30] reported that the antioxidant activity increased with the increase of glucuronic acid content, and the molecular weight of polysaccharides on its antioxidant activity was not significant. This is further supported by Wu et al. who proposed that the high glucuronic acid content of polysaccharides could be one of the main contributors to the antioxidant activity of Leccinum rugosiceps [31].

\section{Materials and methods Materials and regents}

Lenzites betulina fruiting bodies were purchased in April 2017 from Shenzhen Yueyun Trading Co., Ltd., and were identified by associate professor ZHAO Changlin of Southwest Forestry University. A voucher specimen was deposited with the Forestry College of Southwest Forestry University. Cellulose DEAE-52 was purchased from Shanghai Goldwheat biotechnology co., LTD (Shanghai, China). Sephadex G-100 was purchased from shanghai Baoman Biotechnology co. LTD (Shanghai, China). All monosaccharide standards (mannose, rhamnose, galactosamine, glucuronic acid, glucose, galactose, xylose, arabinose, fucose) were purchased from Sigma Chemical Co., Ltd. (St. Louis, MO, USA). All other chemicals reagents were of analytical grade.

\section{Extraction of crude LBPs}

Firstly, dried sample was crushed and then decolorized using 10 -fold volume of ethanol $(80 \%)$ at $60{ }^{\circ} \mathrm{C}$ for $30 \mathrm{~min}$ twice by ultrasonic cleaner (SB25-12DTDS, Ningbo Xinyi Ultrasonic equipment co., Ltd), and the organic layer was removed by suction filtration. The residue was extracted under the conditions of cellulase dosage of $0.8 \%$, enzymolysis temperature of $60{ }^{\circ} \mathrm{C}$, enzymolysis time of $180 \mathrm{~min}, \mathrm{pH}$ of 4.5 , liquid-solid ratio of $45 \mathrm{ml} / \mathrm{g}$, ultrasound power of $300 \mathrm{~W}$, ultrasound time of $20 \mathrm{~min}$ and ultrasound temperature of $45{ }^{\circ} \mathrm{C}$, respectively [32]. Secondly, the supernatant were concentrated and then precipitated with a four-fold volume of anhydrous ethanol at $4{ }^{\circ} \mathrm{C}$ overnight. Then the precipitates were collected by centrifugation at $5000 \mathrm{rpm}$ for $15 \mathrm{~min}$. At last, the crude LBPs was obtained by freeze-drying for $24 \mathrm{~h}$.

\section{Deproteinization of crude LBPs}

Protein in the crude LBPs could has a great interference effect to analysis the structural and biological activity of polysaccharides. In general, deproteinization of polysaccharides was carried out Sevag method [33], briefly, the Sevag solution (chloroform and $n$-butanol, 4:1, v/v) is added in the crude LBPs solution $(1 \mathrm{mg} / \mathrm{mL})$. The 
mixed solution was shocked for 30 min each time, then protein and organic reagent was removed by centrifugation. The content of protein and polysaccharides in the crude LBPs were determined according to coomassie bright blue method and phonel-sulfate method [34]. The remove rate of protein in LBPs was calculated by a bovine serum albumin standard curve, and it was presented as $A=6.739 C-0.0033$ (where $A$ is the absorbance value of sample, $C(\mathrm{mg} / \mathrm{mL})$ is the concentration of bovine serum albumin solution, $\left.R^{2}=0.9998\right)$. The loss rate of polysaccharides in LBPs was calculated by a glucose standard curve and it was presented as $\mathrm{A}=0.016 \mathrm{C}+0.0071$ (where $A$ is the absorbance value of sample, $C(\mathrm{mg} / \mathrm{mL}$ ) is the concentration of glucose solution, $\left.R^{2}=0.9993\right)$. After deproteinization for six times, crude LBPs was obtained by concentrated and freeze dried.

\section{Purification of crude LBPs by DEAE cellulose-52 column} Crude LBPs (30 mg) was dissolved in deionized water (3 $\mathrm{mL})$, and the solution was slowly added to the well-balanced DEAE-52 column using a dropper along the column wall. Gradient elution was sequentially performed with $0,0.1,0.2$ and $0.5 \mathrm{~mol} / \mathrm{L} \mathrm{NaCl}$ solutions at a flow rate of $1 \mathrm{~mL} / \mathrm{min}$, and 100 tubes were collected per gradient for $10 \mathrm{~min}$ each. The phenol-sulfate method was used to detect the polysaccharide content, and the elution curve was plotted according to the content [25]. The two samples with higher polysaccharide content was collected, concentrated and lyophilized to obtain LBPs-1 and LBPs2 . The salt was removed by dialysis and then lyophilized.

\section{Further purification by Sephadex G-100 column}

The two polysaccharide fraction obtained in the previous step was mixed with $10 \mathrm{~mL}$ of a $3 \mathrm{mg} / \mathrm{mL}$ solution in deionized water and slowly added to the equilibrated Sephadex G-100 column. Elution was performed with deionized water at a rate of $0.3 \mathrm{~mL} / \mathrm{min}$, and elution fractions were automatically collected, $10 \mathrm{~mL}$ per tube. The phenol-sulfate acid method was used to detect the absorbance of the collected samples and to draw the elution gradient curve [25]. The sample with the highest polysaccharide content was selected and collected by a rotary evaporator, concentrated, dialyzed, desalted and lyophilized to obtain pure LBPs-5 and LBPs-6.

\section{FT-IR analysis}

FT-IR spectra of LBPs-5 and LBPs-6 were analyzed using a FT-IR spectrophotometer (spectral resolution of $1 \mathrm{~cm}^{-1}$, scanned for 32 times) in the range of $400-$ $4000 \mathrm{~cm}^{-1}$. Approximately $1 \mathrm{mg}$ samples were mixed with $100 \mathrm{mg}$ dried $\mathrm{KBr}$ powder and then pressed into pellets for the FT-IR measurement [35].

\section{Analysis of monosaccharide composition of LBPs-5 and LBPs-6}

The monosaccharide composition of LBPs- 5 and LBPs- 6 were determined using the high-performance liquid chromatography (HPLC) analysis of monosaccharide derivatives with 1-phenyl-3-methyl-5-pyrazolone (PMP) according to the method of $\mathrm{Li}$ et al. [36]. In brief, the two polysaccharide sample $(2 \mathrm{mg})$ and monosaccharide standard were added $1 \mathrm{~mL}$ trifluoroacetic acid (TFA, $2 \mathrm{M}$ ) to hydrolyze at $110{ }^{\circ} \mathrm{C}$ for $4 \mathrm{~h}$, respectively. After hydrolysis, methanol solution was added and then evaporated to remove excess TFA. The PMP derivatization method was as follows: $50 \mu \mathrm{L}$ hydrolysate of the different sample was pipetted into $50 \mu \mathrm{L} \mathrm{NaOH}$ solution $(0.6 \mathrm{M})$ and mixed well, respectively. Then the mixture was added in $100 \mu \mathrm{L}$ of methanol solution of PMP $(0.5 \mathrm{M})$. The following reaction took place in a constant temperature drying oven at $70{ }^{\circ} \mathrm{C}$ for $30 \mathrm{~min}$, and then removed it and cooled down. Next, $100 \mu \mathrm{L}$ hydrochloric acid $(0.6 \mathrm{M})$ was added for neutralization, and the mixture was extracted three times with chloroform. The aqueous layer was filtered through a $0.22 \mu \mathrm{m}$ membrane and analyzed by HPLC. The samples $(20 \mu \mathrm{L})$ were injected into an Agilent system (Agilent Technologies Inc. USA) equipped with a C18 column $(150 \mathrm{~m} \times 4.6 \mathrm{~mm} \times 5 \mu \mathrm{m})$. Acetate Buffer $(0.1 \mathrm{M})$-acetonitrile $(83: 17, \mathrm{~V} / \mathrm{V})$ was used as the mobile phase at a flow rate of $1.0 \mathrm{~mL} / \mathrm{min}$, and the column oven temperature was $30^{\circ} \mathrm{C}$.

\section{Determination of the molecular weight of LBPs-3 and LBPs-4}

High-performance gel permeation chromatography (HPGPC) was used to measure the molecular weight of the polysaccharide fraction after two stepwise purifications of DEAE-52 and G-100 [37]. The molecular weight of the two water-soluble polysaccharides (LBPs-5 and LBPs-6) were evaluated using a HPGPC system (Agilent 1260 HPLC system) equipped with a Shodex Ohpak SB-806 HQ gel column and differential detector. In addition, $0.1 \mathrm{M}$ sodium chloride solution was used as the mobile phase, the flow rate was $0.5 \mathrm{~mL} / \mathrm{min}$, and the column temperature was 35 ${ }^{\circ} \mathrm{C}$. At the same time, the glucan standards whose molecular weight range was close to that of the samples were selected (the molecular weight was $2.5,4.6,7.1,10,21.4$, $41.1,84.4$ and $133.8 \mathrm{kDa}$ ) as a standard curve, according to the standard curve to obtain a linear regression equation as follows: $y=-1.7568 x+2.334\left(R^{2}=0.9976\right)$; where $y$ is the logarithm of the molecular weight of the polysaccharide; $x$ 
is the retention time of the glucan standards (min). After this, $20 \mu \mathrm{L}$ of the standard and sample were injected, and the data were analyzed using Agilent GPC software. Based on the retention time of the polysaccharide on the column and the standard glucan molecular weight curve of the column, the molecular weight of LBPs- 5 and LBPs- 6 were calculated.

\section{Antioxidant activity assays}

The two water-soluble polysaccharides (LBPs-5 and LBPs6) were prepared above was diluted with distilled water into different concentrations of 0.01, 0.05, 0.1, 0.51 .0 and $1.5 \mathrm{mg} / \mathrm{mL}$. The antioxidant activity was investigated by scavenging activity of DPPH., ABTS $^{+}, \cdot \mathrm{OH}$ and total reducing power. A positive control of $\mathrm{Vc}$ was used.

\section{Scavenging effect on DPPH.}

The DPPH. scavenging activity was determined according the method of Wang et al. [38] with slight modifications. Briefly, $2 \mathrm{~mL}$ of $0.2 \mathrm{mM}$ DPPH dissolved in absolute ethyl alcohol was added to $2 \mathrm{~mL}$ of sample. Then the mixture was kept in the dark for $30 \mathrm{~min}$ at room temperature, and the absorbance was recorded at $517 \mathrm{~nm}$. The DPPH. scavenging activity was calculated as follows:

$$
\begin{aligned}
& \text { DPPH } \cdot \text { scavenging activity }(\%) \\
& \quad=\left[1-\left(A_{1}-A_{2}\right) / A_{0}\right] \times 100,
\end{aligned}
$$

where $A_{1}$ is the absorbance value of sample, $A_{2}$ is the background absorbance value (absolute ethyl instead of DPPH solution), and $A_{0}$ is the absorbance value of the blank (absolute ethyl instead of the sample).

\section{Scavenging effect on ABTS.+}

The scavenging activity of ABTS ${ }^{+}$was carried out according to the previous method [39]. In ordering to generate $\mathrm{ABTS}^{+}$, an equal volume of $7 \mathrm{mM}$ ABTS and $2.45 \mathrm{mM}$ potassium persulfate solutions were mixed and allowed to stand in the dark at room temperature overnight. Then the mixture was diluted with absolute ethyl alcohol, and used for the assay. $2 \mathrm{~mL}$ of the sample was added into $2 \mathrm{~mL}$ of the mixture, after $5 \mathrm{~min}$ of incubation in the dark at room temperature. The absorbance value was measured at $734 \mathrm{~nm}$ and the $\mathrm{ABTS}^{+}{ }^{+}$scavenging activity was determined by the following equation:

$$
\begin{aligned}
& \mathrm{ABTS}^{+} \text {scavenging activity (\%) } \\
& \quad=\left[1-\left(A_{1}-A_{2}\right) / A_{0}\right] \times 100,
\end{aligned}
$$

where $A_{1}$ is the absorbance value of sample, $A_{2}$ is the background absorbance value (absolute ethyl instead of the mixture), and $A_{0}$ is the absorbance value of the blank (absolute ethyl instead of the sample).

\section{Scavenging effect on $\cdot \mathrm{OH}$}

The $\cdot \mathrm{OH}$ scavenging activity was measured according to a reported method described previously [40] with little modifications. In briefly, $0.2 \mathrm{~mL}$ of ferrous sulfate $(3 \mathrm{mM})$ and $0.2 \mathrm{~mL}$ of salicylic acid-ethanol $(6 \mathrm{mM})$ were added to $1 \mathrm{~mL}$ of sample solution, $0.2 \mathrm{~mL}$ of hydrogen peroxide $(4 \mathrm{mM})$ was added finally to start the reactions, then incubated at room temperature for $60 \mathrm{~min}$. The absorbance value was calculated at $510 \mathrm{~nm}$. The $\cdot \mathrm{OH}$ scavenging activity was calculated using the following formula:

$$
\begin{aligned}
& \text { ABTS }^{++} \text {scavenging activity (\%) } \\
& \quad=\left[1-\left(A_{1}-A_{2}\right) / A_{0}\right] \times 100
\end{aligned}
$$

where $A_{1}$ is the absorbance value of sample, $A_{2}$ is the background absorbance value (distilled water instead of hydrogen peroxide), and $A_{0}$ is the absorbance value of the blank (absolute ethyl instead of the sample).

\section{Total reducing power assay}

The total reducing power of polysaccharides was measured by the method of $\mathrm{Li}$ [41] with some modifications. A volume of $1 \mathrm{~mL}$ of sample solution was mixed $2.5 \mathrm{~mL}$ phosphate buffer ( $\mathrm{pH} 6.6,0.2 \mathrm{M}$ ) and $2.5 \mathrm{~mL}$ of potassium ferricyanide solution $(1 \%, \mathrm{~W} / \mathrm{V})$, and then the mixture was incubated at $50{ }^{\circ} \mathrm{C}$ for $20 \mathrm{~min}$. Then $2.5 \mathrm{~mL}$ trichloroacetic acid $(10 \%, \mathrm{~W} / \mathrm{V})$ was added into the mixture and centrifuged at $3500 \mathrm{rpm}$ for $10 \mathrm{~min} .2 .5 \mathrm{~mL}$ of the supernatant was mixed with $2.5 \mathrm{~mL}$ of distilled water and $0.5 \mathrm{~mL}$ of ferric chloride solution $(0.1 \%$, $\mathrm{W} / \mathrm{V}$ ) at room temperature for $15 \mathrm{~min}$. The absorbance value of the reaction mixture was measured at $700 \mathrm{~nm}$.

\section{Statistical analysis}

All experiments were repeated at least three times, statistical analysis was carried out using Originpro 2017C (OriginLab Co., USA) and SPSS 20.0.0 statistics software (IBM Co., USA). All values were presented as the mean $\pm \mathrm{SD}$, multi-group mean comparison was analyzed by one-way variance, and pairwise comparison was performed by LSD test. Significance difference was set at $p<0.05$.

\section{Conclusions}

In this study, two water-soluble polysaccharides LBPs-5 and LBPs- 6 were isolated from Lenzites betulina using cellulase-ultrasonic synergistic extraction method, successfully purified via DEAE cellulose-52 and sephadex G-100 column and characterized by a combination of chemical and instrumental analysis methods. The strong antioxidant activities indicates the two water-soluble polysaccharides have potential as a source of natural 
antioxidants with potential application in reducing oxidative stress with consequent health benefits. Anyway, the antioxidant mechanism of the two water-soluble polysaccharides is still not clear and thus further work is required to clarify the possible antioxidant and antitumor mechanism and of Lenzites betulina polysaccharides.

\section{Acknowledgements}

The authors are highly thankful to the Key Laboratory for Forest Resources Conservation and Utilization in the Southwest Mountains of China, Ministry of Education, Southwest Forestry University for providing essential experimental facilities to complete the research study.

\section{Authors' contributions}

$L G$ and YH designed the work, LG and HD carried out the experimental part. $L G, J M$ and JW collected and analyzed the data, and drafted the manuscript. $L G, Y H$ and $L Z$ revised manuscript draft. All authors read and approved the final manuscript.

\section{Funding}

This work was financially supported by the Scientific Research Fund Project of Yunnan Provincial Department of Education (2020Y0413).

\section{Availability of data and materials}

The datasets used and/or analysed during the current study are available from the corresponding author on reasonable request.

\section{Ethics approval and consent to participate}

Not applicable.

\section{Consent for publication}

Not applicable.

\section{Competing interests}

The authors declared no potential conflicts of interest with respect to the research, authorship, and/or publication of this article.

\section{Author details}

${ }^{1}$ Key Laboratory for Forest Resources Conservation and Utilization in the Southwest Mountains of China, Ministry of Education, Southwest Forestry University, Kunming, People's Republic of China. ${ }^{2}$ School of Life Science, Southwest Forestry University, Kunming, People's Republic of China. ${ }^{3}$ School of Pharmacy, Wannan Medical College, Wuhu, People's Republic of China.

Received: 16 December 2020 Accepted: 8 February 2021 Published online: 17 March 2021

\section{References}

1. Song JB, Chen M, Li ZQ, Zhang JF, Hu H, Tong XL, Dai FY (2019) Astragalus polysaccharide extends lifespan via mitigating endoplasmic reticulum stress in the silkworm, Bombyx mori. Aging Dis 10:1187-1198

2. Wu MQ, Xia W, Xu ZZ, Song JX, Chen LN, Zhang WQ (2019) Review on isolation and purification, structural elucidation and biological activity of botanical polysaccharides. Chem world 60:737-747

3. Liang X, Ni XZ, Han LP (2018) Advances in bioactivities of polysaccharides from edible medicinal fungi. J Changchun Norm Uni 3:82-85

4. Janjušević L, Karaman M, Šibul F, Tommonaro G, Lodice D, Pejin B (2017) The lignicolous fungus Trametes versicolor (L.) Lloyd (1920): a promising natural source of antiradical and AChE inhibitory agents. J Enzyme Inhib Med Chem 32:355-362

5. Pejin B, Tešanović K, Jakovljević D, Kaišarević S, Šibul F, Rašeta M, Karaman M (2017) The polysaccharide extracts from the fungi Coprinus comatus and Coprinellus truncorum do exhibit AChE inhibitory activity. Nat Prod Res 33:750-754

6. Lu HY, Zhang XP (2018) Effect of lentinan on infiltrating lymphocytes of tumor tissue and peripheral blood in breast cancer patients undergoing neoadjuvant chemotherapy. J Anhui Med Pharm 22:2427-2431
7. Gan N, Wu XY, Zheng CJ, Yin H, Wu SL (2017) Study on the antitumor activity of Auricularia auricula polysaccharides on B16 melanoma cells. J Guangdong Pharm Univ 33:758-762

8. Irinoda K, Masihi KN, Chihara G, Kaneko Y, Katori T (1992) Stimulation of microbicidal host defence mechanisms against aerosol influenza virus infection by lentinan. Int J Immunopharm 14:971-977

9. Wei H, Zhang D, Lu L, Chen FC (2017) Extraction, purification and antioxidant activities of several polysaccharides from edible and medicinal fungi. J Nanjing Norm Univ (Nat Sci Ed) 40:72-88

10. Wang YS, Zheng XX, Li FK, Yang Y, Wang H, Lv SJ (2019) Advances in pharmacological action of polysaccharides from edible-medicinal fungi and its application in veterinary clinic. Chin Anim Husband Veter Med 46:3106-3114

11. Wen CN, Chen HP, Zhao ZZ, Hu DB, Li ZH, Feng T, Liu JK (2017) Two new $\gamma$-lactones from the cultures of basidiomycete Lenzites betulinus. Phytochem Lett 20:9-12

12. Shen XY, Ma T, Ma X, Huang YT, Liu CL (2017) Isolation, purification and free radical scavenging activities of polysaccharide from Lenzites betulina. Mycosystema 36:1271-1277

13. Liu K, Wang JL, Liu MF, Bi KL, Song YF (2011) Medical macrofungi resources and diversity in inner Mongolia. J Hebei Univ (Nat Sci Ed) 31:508-514

14. Fujimoto H, Nakayama M, Nakayama Y, Yamazaki M (1994) Isolation and characterization of immunosuppressive components of three mushrooms, Pisolithus tinctorius, Microporus flabelliformis and Lenzites betulina. Chem Pharmaceut Bull 42:694-697

15. Liu K, Wang JL, Wu HB, Wang Q, Bi KL, Song YF (2012) A new pyranone from Lenzites betulina. Chem Nat Compd 48:780-781

16. Ren G, Liu XY, Zhu HK, Yang SS, Fu CX (2006) Evaluation of cytotoxic activities of some medicinal polypore fungi from China. Fitoterapia 77:408-410

17. Li LY, Huang T, Liu HM, Zang JL, Wang P, Jiang XL (2019) Purification, structural characterization and anti-UVB irradiation activity of an extracellular polysaccharide from Pantoea agglomerans. Int J Biol Macro 137:1002-1012

18. Boulet JC, Williams P, Doco T (2007) A Fourier transform infrared spectroscopy study of wine polysaccharides. Carbohydr Polym 69:79-85

19. Yang YR, Hao ZQ, Chang MC, Meng JL, Liu JY, Feng CP (2019) Isolation, purification, structural identification and antioxidant activity of acidic polysaccharide in Sparassis crispa. Acta Edulis Fungi 26:105-112

20. Jeong HK, Lee D, Kim HP, Baek SH (2019) Structure analysis and antioxidant activities of an amylopectin-type polysaccharide isolated from dried fruits of Terminalia chebula. Carbohydr Polym 211:100-108

21. Cai M, Chen S, Luo SL, Yang K, Sun PL (2019) Comparison of membrane separation and alcohol precipitation for the separation of crude polysaccharides from Hericium erinaceus. Food Chem 40:83-90

22. Liu F, Chen GT, Hu QH, Zhao SW, Zhao LY (2014) Separation, purification and structure characteristics of Zn-binding polysaccharides from Flammulina velutipes. Food Chem 35:1-7

23. Chen SS, Wu B, Tan T, Xie SS, Yang SL, Feng YS, Wen Q (2019) Isolation, purification and structural characterization of Bletilla striata polysaccharides and its antitumor activity. Chin Trad Herbal Drugs 50:1921-1926

24. Brand-Williams W, Cuvelier ME, Berset C (1995) Use of a free radical method to evaluate antioxidant activity. LWT Food Sci Technol 28:25-30

25. Benvidi SMH, Jahanbin K (2020) A new water-soluble polysaccharide from Echinops pungens Trautv roots. Part I. Isolation, purification, characterization and antioxidant activity. Int J Biol Macromole 161:909-916

26. Liu YQ, Hao LM, Lu JK, Cui Y, Zheng ZQ, Zhang LM, Jia SR (2019) Antioxidant activity of Ganodermalucidum fruit body and spore powder polysaccharide. Sci Technol Food Ind 40:27-31

27. Chen YX, Liu XY, Zheng X, Huang YF, Liu B (2016) Antioxidant activities of polysaccharides obtained from Chlorella pyrenoidosa via different ethanol concentrations. Int J Biol Macromole 91:505-509

28. Fan LP, Li JW, Deng KQ, Ai LZ (2012) Effects of drying methods on the antioxidant activities of polysaccharides extracted from Ganoderma lucidum. Carbohyd Polym 87:1849-1854

29. Gordon MH (1990) The mechanism of antioxidant action in vitro. In: Hudson BJF (ed) Food antioxidants. Elsevier Applied Science, London, UK, pp 1-18 
30. Wu YL, Shao ZL, Zhang Y, Wang YL, Zhao ZM (2019) Isolation, purification and antioxidant activity of pumpkin homogeneous polysaccharide. Food Res Develop 40:62-70

31. Wu Y, Xu F, Li XS, Zhu JH, Shen LQ (2020) Structural elucidation and antioxidant activity of LRP-I and LRP-II polysaccharide from Leccinum rugosiceps. Sci Technol Food Ind 41:8-14

32. Guo L, Tan DC, Hui FY, Gu F, Xiao KM, Hua Y (2019) Optimization of the cellulase-ultrasonic synergistic extraction conditions of polysaccharides from Lenzites betulina. Chem Biodiver 16:e1900369

33. Qin WD, Ma LH, Chen XH, Zhao Y (2008) Study on extraction and deprotein of polysacharide in ginger. Food Chem 29:218-220

34. Wang LW, Ou YZ, Zhang BJ, Yang Q, Wang DJ, Yu YF, Zhang J, Ma Q (2017) Deproteinization and structural analysis of polysaccharides from Dendrobium officinale Kimura et Migo grown in Huoshan. Food Chem 38:164-170

35. Wang YP, Wang CN, Guo MR (2019) Effects of ultrasound treatment on extraction and rheological properties of polysaccharides from Auricularia Cornea var. Li. Molecules 24:939

36. Li SF, Wang AJ, Tian GR, Liu LN, Wei SX (2018) Column chromatographic purification and monosaccharide composition of polysaccharide extracted from Agaricus bisporus stipe. Sci Technol Food Ind 39:16-20
37. Zhang ZP, Shen CC, Gao FL, Wei H, Ren DF, Lu J (2017) Isolation, purification and structural characterization of two novel water-soluble polysaccharides from Anredera cordifolia. Molecules 22:1276

38. Wang XZ, Li F, Zhao YZ (2019) Study on ultra-high pressure extraction of Aurea helianthustems polysaccharides and its antioxidant activity. Cereal Oils 32:85-88

39. Venkatesan T, Choi YW, Kin YK (2019) Effect of an extraction solvent in the antioxidant quality of Pinus densiflora needle extract. J Pharm Analysis 9:193-200

40. Cai LL, Chen BH, Yi FL, Zou SS (2019) Optimization of extraction of polysaccharide from dandelion root by response surface methodology: structural characterization and antioxidant activity. Int J Biol Macromol 140:907-919

41. Li H (2017) Extraction, purification, characterization and antioxidant activities of polysaccharides from Ramaria botrytis (Pers.) Ricken. Chem Cent J 11:24

\section{Publisher's Note}

Springer Nature remains neutral with regard to jurisdictional claims in published maps and institutional affiliations.
Ready to submit your research? Choose BMC and benefit from:

- fast, convenient online submission

- thorough peer review by experienced researchers in your field

- rapid publication on acceptance

- support for research data, including large and complex data types

- gold Open Access which fosters wider collaboration and increased citations

- maximum visibility for your research: over $100 \mathrm{M}$ website views per year

At $\mathrm{BMC}$, research is always in progress.

Learn more biomedcentral.com/submissions 